\title{
Diversity and equality in honours and awards programs - steps towards a fair representation of membership
}

\author{
Mary Anne Holmes ${ }^{1}$, LaToya Myles ${ }^{2}$, and Blair Schneider ${ }^{3}$ \\ ${ }^{1}$ Department of Earth and Atmospheric Sciences, University of Nebraska-Lincoln, Lincoln, NE 68588-0340, USA \\ ${ }^{2}$ NOAA Air Resources Laboratory Atmospheric Turbulence and Diffusion Division, Oak Ridge, TN, USA \\ ${ }^{3}$ Kansas Geological Survey, 1930 Constant Avenue, Lawrence, KS 66047, USA
}

Correspondence: Mary Anne Holmes (mholmes2@unl.edu)

Received: 5 February 2020 - Accepted: 1 April 2020 - Published: 18 May 2020

\begin{abstract}
Honours and awards bestowed by professional societies recognize and reward members who have advanced the goals and values of that society. All too often, however, awards reflect a small network of people who know about the awards and participate in the process. This network works wonderfully for the people lucky enough to be in it, but typically neglects the full range and breadth of scholarship and service within the society. We represent a combined $15+$ years' experience on the honours' committee for a large professional society (the American Geophysical Union) and here offer strategies to increase the representation of honourees. Women represented less than $20 \%$ of awardees when we first became committee members in 2008; women represented $50 \%$ of awardees in 2019. There is still much to do to ensure that members from other typically underrepresented groups (non-US members, members from underrepresented races/ethnicities) are truly represented and honoured for outstanding science and service. We recommend forming canvassing committees that will scour the literature, conferences, and membership lists for appropriate and otherwise overlooked nominees; providing implicit bias training to selection committees; and ensuring selection committees focus on the criteria for the award rather than non-pertinent, often personal, information, as well as additional strategies that allow us to recognize our worthy colleagues.
\end{abstract}

1 Honours and awards programs: why we have them, and are they inclusive of the entire membership?

Honours and Awards programs within science societies are formed to recognize and honour people in the discipline who promote the values of the organization. These may include scientific advancement, outstanding education, distinguished and prolific mentorship, acting as spokespersons for science to pre-college educators, authors and promoters of science policy, outreach to the public, and service provided to the society. Awardees benefit from recognition by a professional society as their home institutions may use awards to determine promotion, salary raises, and other benefits (Stewart and Valian, 2018; Mason et al., 2014). The institution benefits as well, as high-profile awards bestow prestige and impact in national and international rankings. Early career members tend to view awards as good for their career advancement; later stage career members appreciate the recognition of their peers (unpublished survey data, AGU).

Honours Programs struggle to ensure that awardees look like their membership (e.g., Ball, 2014; Van Miegroet, 2016; AWIS, 2011; Holmes et al., 2011; Lincoln et al., 2012). Examination of data from professional societies reveals that women are typically under-represented among awardees for science honours in the US and Europe and scientists of colour are typically under-represented in the US. By underrepresented in Honours programs, we mean there is a lower percentage in the nominee and awardee pools than occurs in the overall professional society membership, with age and Section (specialty or sub-discipline) considered for career stage- and subdiscipline-specific awards. This definition follows that of the US National Science Foundation 
which defines under-representation in STEM as "representation [that] is smaller in science and engineering than in the US population" (https://www.nsf.gov/news/news_summ. jsp?cntn_id=297944, last access: 30 April 2020). This limited research on who gets honoured currently overlooks the representation of individuals of other under-represented identities in Science, Technology, Engineering and Mathematics (STEM), such as gender identity, sexuality, or ability. Furthermore, research demonstrates that scientists who identify into more than one category for under-representation tend to be overlooked for awards even more, a phenomenon known as "the double bind" (Malcom et al., 1975) or "double jeopardy" (Williams, 2014). Women of colour experience disproportionate levels of isolation and exclusion relative to their white peers (Johnson, 2011), and consequently are even further below the radar of colleagues who nominate (Malone and Barabino, 2009).

Data from the American Geophysical Union (AGU) from the last ten years reveal the under-representation of women and non-US members (based on the primary address provided to AGU) among awardees as well as of US inhabitants from under-represented groups (African American, LatinX, Native American, LGBTQ+). Women and non-US members are also under-represented in nominee pools (Fig. 1) and on selection committees. The data for Fig. 1 are for twenty-six AGU medals, prizes and awards that represent a range of career stages. Because of historical under-representation, the proportion of women members in later career stages is lower than it is among earlier career geoscientists (https://news.agu.org/ files/2017/01/gender-distribution-by-age-group.jpg, last access: 30 April 2020); such facts are considered when determining proportional representation for each award. Early, Mid- and Late-Stage Career stages are defined by AGU based on "years since PhD" and not on absolute ages, such as "3545 years old" (https://www.agu.org/Honor-and-Recognize/ Honors/Nomination-resources/Career-Stages, last access: 30 April 2020), because not all people follow the same career trajectory, and may receive a $\mathrm{PhD}$ later than the US median for Earth, Atmospheric and Ocean Sciences, which is 31 (NSF, 2019).

The proportion of members who are women increased from 2014 to 2019, but the proportion of women nominated for awards fell from 2014 to 2018 (Fig. 1). In 2019, women were "over-represented" among nominees and awardees as members began to notice qualified women who had not been nominated before. We expect several years of such "over-representation" to compensate for years of under-representation. Until 2019, we found women under-represented for awards within every career stage for AGU honours and awards. In addition, women are underrepresented among nominees (Fig. 1) and among nominators.

The proportion of non-US members has remained steady from 2014 to 2019, but the proportion of nominees and honourees has increased as focus on increasing nomina-

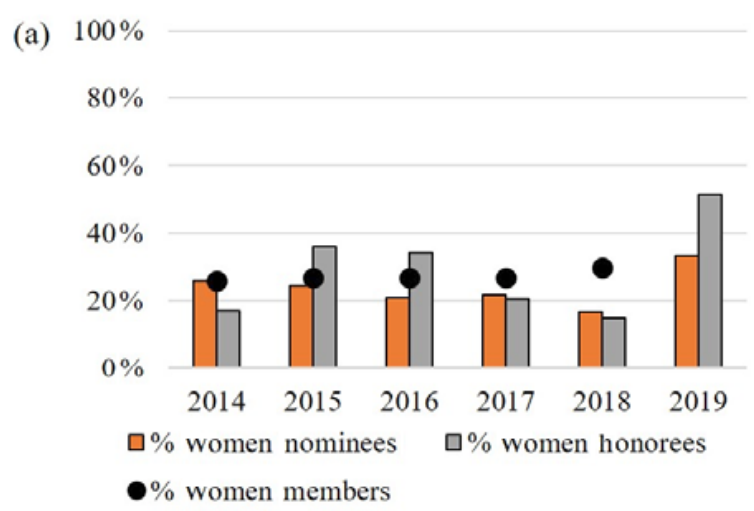

(b) $100 \%$

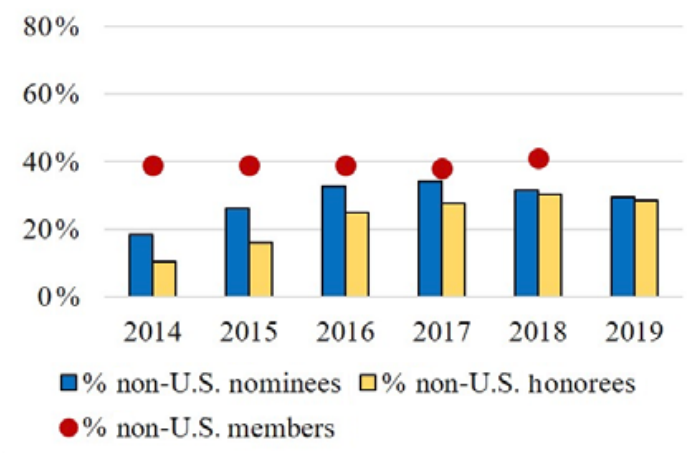

Figure 1. Percentage of women (a) and non-US members (b) for AGU membership (circles), nominees and honourees (bars) for all twenty-six Union-level awards, medals and prizes of women members.

tions overall has increased. From conversations with non-US members on the AGU Honors and Recognition Committee, we suspect that non-US under-representation arises from a number of factors: AGU is not the principal professional geoscience society for non-US members; non-US members find it difficult to serve on AGU committees, which are typically held in the US and require travel, and lack of opportunities to connect with US members who are more likely to participate in the Honors program. In addition, one anecdote reveals a lack of interest in self-promotion that participation in Honours programs implies. The actual reasons for underrepresentation of non-US members requires further study.

We view under-representation in awards programs as a problem for which we offer a set of solutions.

\section{Typical mechanism for granting awards}

The processes for advertising, gathering, and selecting awards varies by award. However, the majority of honours and awards follow a typical mechanism, as outlined below. 


\subsection{Stage 1: award advertisement}

Typically, professional societies announce awards that will be offered within the year, with deadlines for submission of nomination "packets". Members receive these announcements typically by email, social media or by printed matter. The name of the award, the purpose of the award, where and how to submit the packet, and a deadline are generally provided. If the award is named for a person, a brief biography may be provided to serve as a model for the sort of achievements the award is intended for.

\subsection{Stage 2: compiling the "packet"}

The "packet" generally contains a nomination letter from the nominator, a full or abbreviated Curriculum Vitae (C.V.) of the nominee, and letters of support from qualified colleagues. Qualified colleagues are selected based on their familiarity with the qualifications of the nominee and whether they can best address how the nominee fits the criteria for the award. "Qualified" does not necessarily imply "eminence"; people at earlier career stages may have deeper knowledge of the candidate or could speak to non-technical aspects of a nominee.

There may be additional requirements for the packet, such as a comprehensive list of publications, or a short list of the most consequential publications. Some short-cut metrics such as the $h$-index may be required.

\subsection{Stage 3: selection committee review and decision making}

Selection committees receive the nomination packets sometime after the deadline. These committees are assembled by the professional society staff or appropriate members, generally using suggestions from existing committee members or society officers, who typically are past awardees or successful nominators.

Selection committees may deliberate in person, via email or teleconference, or some combination of these in single or multiple meetings. There may or may not be an evaluation rubric provided to the committee in advance. There may or may not be an informational meeting (often with staff) on how to conduct meetings and how to review the criteria for the award. There may be some sort of numeric ranking that may or may not be disseminated to the committee before deliberation. The committee may come to a consensus on the awardee or may require a vote. They may award the person with a majority of votes or may require unanimity.

\section{Is the mechanism part of the problem?}

Although this process is typical for most professional societies, there are key "decision points" at which a step is taken on the road to selecting an awardee that needlessly narrows the field of potential awardees and may increase the chances for highly eligible awardees to be overlooked. One component that plays across all key decision points is implicit bias.

\section{Implicit bias}

Implicit biases arise from unexamined assumptions about our fellow human beings from living within a given culture. In fact, we have a vast array of unexamined assumptions in our brains, but most of these are benign. We often speak to a child in a high-pitched voice, for example. When pressed to ask how we learned to do this, and why, most of us do not know. It may or may not be annoying to the child, but the impact of the unexamined assumption that we must speak to children in this way is not likely to have long-lasting or deleterious effects.

But when our unexamined assumptions include "women aren't good at math" or "women prefer people-helping work", then there can be a negative impact. It may appear small, but it is observable and has been detected in dozens of real-life settings (see summaries of such research in, e.g., Holmes et al., 2015). Some brief examples include: both men and women judge identical C.V.s as "better" when it has a man's name rather than a woman's or simply initials; in the US we judge made-up C.V.s with "white" names as "better" than those with "non-white" names (Boring et al., 2016; Malouff and Thorsteinsson, 2016; Macnell et al., 2015; MossRacusin et al., 2012; Bertrand and Mullainathan, 2004). The impact can be small, but it is additive with each evaluative step. As Valian (1999) puts it, it becomes a mountain of molehills.

Importantly, implicit biases and their underlying unexamined assumptions are shared by all of the people within a given culture: men and women both may show a subtle (to not-so-subtle) bias towards men for both nominating and selecting our colleagues for awards. Research demonstrates that while we cannot eliminate implicit biases, we can become aware of them and reduce their impact on evaluation.

\section{Implicit bias impacts on awards programs}

Implicit biases impact multiple stages of the awards process: who sees the award advertisement, who feels competent in making a nomination, who gets noticed for awards, how we learn to navigate the nomination process, how we write letters of recommendation, what shortcut metrics are used, such as the $h$-index. The actual selection process is replete with opportunities for biases to rear their ugly heads: who gets to serve on the selection committee, what training does the committee receive to ensure the conversation stays focused on the award criteria and not on personal attributes of the nominees? 
In addition to implicit bias, mechanisms of the process may unintentionally reduce the pools of both nominators and nominees in awards programs. We address problems for each major stage of the process.

\subsection{Stage 1: award advertisement}

Ideally, advertising ensures that as many members of the scientific community as possible will learn about the program and consider participating. The wording of the ad (are gender-specific nouns and adjectives used?) as well as any photos (who is represented as worthy of an award?) may expand or reduce the potential pools of nominators and nominees. The very name of the award may invite inclusion or promote exclusion. The relevance of an award, and the person for whom it is named, varies with time as our field evolves. We have heard younger scientists ask, "who is that?", referring to an award named for a scientist whose work was highly relevant decades ago.

\subsection{Stage 2: compiling the "packet"}

\subsubsection{Whom to nominate}

The first step in compiling a packet is determining who will be nominated, a process that can be impacted by implicit bias: we tend to nominate women for service and education awards and nominate men for research awards (Lincoln et al., 2012). How does a scientist think of whom to nominate, or who might nominate me? Who has had the exposure, via mentoring or example, to know about awards processes and how to engage in them, i.e., how to write a successful nomination? Data from AGU indicate that a very small cadre, less than $1 \%$, of members participate in the awards program. These members typically come from a small number of institutions, often where previous awardees reside. Often, these awardees know details about the awards and learned how to put together successful nomination packets by learning it from mentors and colleagues.

There are myriad reasons that propel individuals to identify and nominate candidates for awards. In most scientific societies, any member can serve as a nominator. However, there are often perceived benefits to nominations supported by past award winners or others with prestige and influence in the organization or scientific discipline (James et al., 2019), whether this is true or not. Table 1 provides common misperceptions about awards programs.

In addition, we tend to nominate from our own professional and social networks. A recent study by Hanson et al. (2019) analysed abstracts submitted for the AGU Fall Meetings from 2014-2018 and evaluated the author network by gender and geographic location. Their results revealed that women tended to have author networks made up of other women, and their networks had fewer international coauthors than the men's networks.

\subsubsection{Bias in nomination and support letters}

Men and women write letters of recommendation differently based on the gender and race of the nominee (Madera et al., 2019, 2009; Dutt et al., 2016; Schmader et al., 2007; Trix and Psenka, 2003). These studies show that letters for males contain more superlatives, more direct callouts to the nominee's C.V. and accomplishments, and avoid comments about non-professional traits. Letters for women contain personal comments, such as whether she is married or has children, personality traits, such as "she is nice" or "she is friends with my wife". There are more "doubt raisers" in women's letters, such as the use of less-than-superlative adjectives.

\subsubsection{Bias in shortcut metrics}

Many evaluations use numeric shortcuts to assess a scientist's productivity, but some of these have inherent biases. The $h$-index, for example, is calculated differently by different databases. Databases are not perfect and can miss references that have differing first names, use of initials, or if the last name has changed over the course of a career (generally, a "woman's problem"). The $h$-index increases with increasing age and is generally larger for men because of self-citation (King et al., 2017; Maliniak et al., 2013).

\subsection{Stage 3: selection committee review and decision making}

Many scientific societies rely on committees of volunteers to manage the honours and awards program. Typically, selection committees are charged with (1) establishing a review process which aligns with strategic goals, organizational values, and established criteria; (2) employing the process to evaluate nomination packages; and (3) reaching consensus to select a nominee for recognition (AWIS, 2011; Fine and Paredes, 2012). Most selection committees are composed of three or more members led by a chairperson, who is either appointed by the society or elected by committee members. While the structure of selection committees seems transparent, the identification of volunteers to serve on these committees as well as the guidelines under which they operate are often ambiguous (Lincoln et al., 2011). Thus, the actual evaluation can be rife with bias, beginning with the selection of the committee itself. Does the selection committee have broad representation? How do members learn about opportunities to serve on the committee? How often do committee members rotate on and off?

The perception of how best to evaluate the nominees can vary by individual. Are the criteria for the award clear to the committee members? Does the committee have an established rubric to evaluate nomination packets before they begin to read them? With no rubric, it is easy to stray to a nominee's personal attributes, anecdotes, and other irrelevant information that can steer a discussion off course. It is also 
Table 1. Common myths and misconceptions about awards programs.

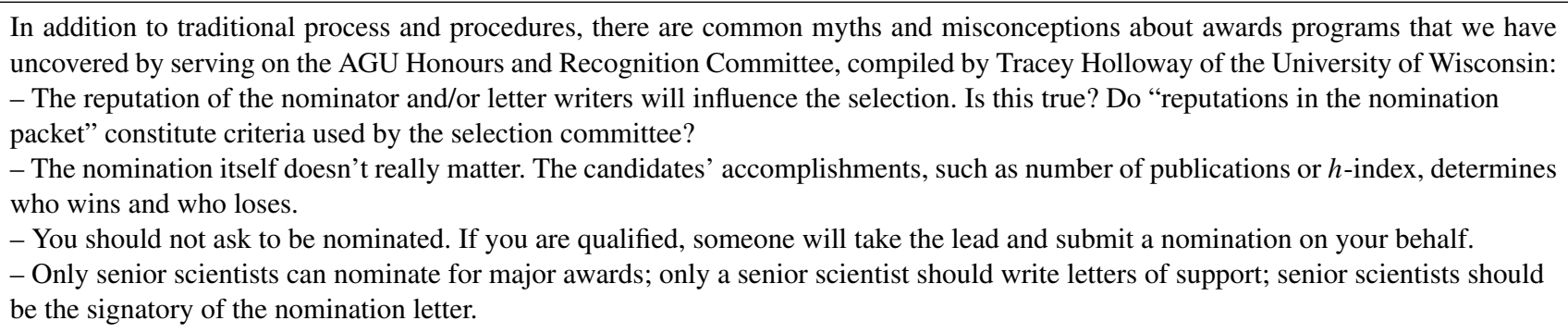

important to consider if committee members have been informed of criteria that should not be addressed as well, such as marital or parental status.

After the nomination packets have been distributed and reviewed by committee members, how the results are compiled and reviewed can enhance or reduce bias. If committee members send rankings of a nominee pool to the entire committee, "anchoring bias" can be triggered. This is the human tendency to "anchor" subsequent decisions on a given, early acquired piece of information (Kahnemann, 2011).

How the discussion meeting, if any, proceeds can influence the decision. The meeting may be online, over the phone, or in-person, depending on the committee. Have the committee members received any training on how to conduct meetings in a civil manner? Is there an agenda set to work through the process? Has someone been assigned to take notes, or is the meeting being recorded for record-keeping purposes? People have been known to hijack meetings for their own ends, or if working remotely, pay little or no attention as they surf the web or do other work during the meeting. These behaviours can influence the selection outcome.

\section{Solutions to improve diversity and inclusivity in honours and awards}

The key decision points that impact demographic representation in the honours and awards process is extensive, and those identified above are not exhaustive. Each point accumulates barriers that individuals from under-represented groups have to face just to make it to the selection committee review stage of the process. However, there are solutions that we can implement to improve diversity and inclusivity in honours and awards nominations.

\subsection{The nomination process}

\subsubsection{Getting the word out: announcing the award}

A professional society interested in how effective their award advertising is could collect data on how nominators learn about the awards. A simple question asked on the nomination form, "How did you hear of this award?" with a drop- down list (including "other") of announcement venues will reveal how a society is getting the best response. If "word of mouth" is the most common response, further steps may need to be taken: why are printed materials/social media not reaching members? Means of getting the word out have changed dramatically in the last decade: announcements that are distributed via email are possibly not even being opened by large numbers of scientists, but only announcing awards on social media may exclude a significant portion of the scientific community as well. Utilizing multiple modes to announce an award makes the process more accessible to all.

Societies also need to consider how the award itself is presented. Would a typical member feel motivated to make a nomination based on what is in the announcement? Selection criteria written in highly discipline-specific terminology could be off-putting for individuals considering who they could nominate that fits those specific research goals. On the other hand, if the criteria are too broad then a nominator may interpret it differently than the selection committee will. Consider also the images and graphics associated with the award announcement. Are prior awardees showcased, and do these awardees represent the range of members of the society? If they don't, how could you change your advertisements to reflect the diversity of candidates eligible for these awards?

Is more information on the nomination process needed? How can a professional society reach members who have no experience with the awards process? One mechanism modelled by AGU includes offering a workshop at its principal annual meeting on the theme "How to Submit a Successful Nomination". It is generally well-attended, with as many as 120 members signing up to attend. This workshop focuses on the impact of implicit bias in our nominations and provides strategies to reduce them. However, offering a single workshop at a single meeting isn't accessible to everyone. Consider the needs of those who cannot attend meetings and offer an online workshop that can be watched at any time. Articles in the newsletter can offer the mentorship that may be missing in a potential nominator's experience (e.g., Ball et al., 2015). Professional societies can also develop lists of frequently asked questions that can be advertised across multiple media avenues to quell common misconceptions. 
The society can assist its members by providing a generic, sample nomination packet and providing clear instructions (AGU provides a video) on how to navigate the online nomination submission, if used. The award criteria should be clearly spelled out. Vague words such as "excellence" should be avoided or clarified.

\subsubsection{Broadening the nomination pool: networks and canvassing committees}

The implicit biases that aggregate over a career limit our exposure to other scientists, particularly scientists that "don't look like me". Nominators should consider expanding their networks to become aware of candidates who have demonstrated exceptional achievements, perhaps with less attention or acclaim. For example, nominators can engage with potential nominees through mentoring programs or by becoming active in professional societies and employee resource groups that foster advancement of those who have been historically under-represented in science (Débarre et al., 2018; Fine and Paredes, 2012). Expansion of professional networks also offers benefits beyond the honours process, including new collaborations and ideas which strengthen the overall scientific enterprise. In recent years, the National Science Foundation (NSF) GEO Opportunities for Leadership in Diversity (GOLD) program (https://cpaess.ucar.edu/gold, last access: 30 April 2020) supported a series of projects to train and empower geoscientists as change agents for diversity and inclusion in their networks and their broader fields of study (Posselt et al., 2019). One of the projects, Hearts of GOLD, specifically sought to equip senior scientists with knowledge and tools to catalyse, develop, and institutionalize more representative practices for diversity and inclusion in the geosciences (Quardokus Fisher et al., 2019). NSF's GOLD and similar programs can help identify potential nominees and foster more balanced representation among award recipients.

Another successful approach to garnering more inclusive nominations for honours and awards is the implementation of a committee to serve as scouts for potential awardees: a canvassing committee. While selection committees are focused on the task of choosing the most-deserving award recipients from among nominees, canvassing committees are charged with increasing the number of nominations, which may be achieved by identifying nominators and nominees, providing assistance in crafting nomination packages, and offering training and resources for potential nominators to ensure a diverse pool of candidates. A canvassing committee that is itself diverse and representative may be more aware of deserving candidates who have not been previously considered for recognition. To be successful, a canvassing committee should be overseen by society staff and/or the society's honours program to ensure its membership is diverse (consider all career stages, men, women, national and international members, members from all groups traditionally under-represented in the geosciences). The committee should receive training to help identify their own implicit biases. In addition, the charge of the committee must be clear to all of the members: to increase the number of nominations and the diversity of the nominees. This committee should serve to broaden the net that is cast to bring in nominations, not to filter the pool further. Continuous data collection should inform both this committee and its oversight by some other entity. That is, it must be held accountable. This raises the question of what entity holds this committee accountable; this should be clear in the committee's charge.

Some well-resourced institutions have gone beyond voluntary canvassing committees and hired permanent staff who facilitate award nominations. They draft sample letters of support, contact potential letter-writers, work with nominators and pull the packet together in a timely fashion. Lessresourced institutions cannot do this; their faculty are thus at a disadvantage for being noticed for an award as well as having the time and resources to put together competitive nomination packets. One way to address this inequity is demonstrated by informal groups that have formed among AGU members to identify worthy yet overlooked potential nominees and help each other create the nomination packet (e.g., Jaynes et al., 2019). The Task Force described by Jaynes et al. (2019) set up an online space where names of potential nominees, nominators and letter-writers could be gathered. The letters themselves can be reviewed by Task Force members and suggestions for improvements made. This ad hoc Task Force generated six nomination packets, and three of their nominees received national awards. This is one way to mentor neophytes into the process of nomination. Some organizations have more formal, employee resource groups (ERGs) to pool resources to submit nomination packets

\subsection{Selection processes}

\subsubsection{Establish a representative selection committee}

Assembling a diverse selection committee is a key step, as several formal studies have demonstrated that conscious and unconscious bias towards male candidates can be mitigated by having different kinds of voices at the table (Carnes et al., 2005; James et al., 2019; Lincoln et al., 2012). Biases can also occur when committees do not include members of different nationalities or members from underrepresented racial or ethnic groups or nations, so ensure the committee has the diverse voices it needs (AWIS, 2011; Mukasa, 2009). To mitigate biases, societies can take a more inclusive approach to ensure that selection committees represent the genders, nationalities, ethnicities, career-stages, and backgrounds of the broader scientific community. Research demonstrates that women perform more service tasks in academia (O'Meara et al., 2017). To mitigate this imbalance, several academic institutions in the US have instituted "Male Advocates and Allies" (https://www.ndsu.edu/forward/advocates_and_allies_ project/about_advocates_allies/, last access: 30 April 2020). 
These male faculty and staff receive sufficient training in implicit bias and how to mitigate its impact to serve as a voice for the under-represented. In addition, societies can limit the terms of service (by years or award cycles) for selection committees, which can provide opportunities for new members who may be more representative of changing demographics within the organization's membership.

\subsubsection{Train committee members - and chair}

Selection committee members should receive training in Leading Practices for evaluations before any evaluation occurs. The training should include a discussion of implicit biases, when they are most likely to occur, and what steps minimize their impact. A clear procedure should be established that outlines whether there will be meetings and what will be covered at each. For example, will there be an initial meeting to discuss and establish procedure, including the criteria for selecting the nominee, before committee members see the packets? All members will benefit by training in any online software used by the society.

Nominators and support letter writers should become aware of the tendencies for all of us to unconsciously bias our letters and carefully read our letters, more than once, to assure that the language they use to describe a nominee is not unintentionally pushing them out of the pool. When selection committee members recognize bias in the letters, they may be able to adjust accordingly (for example, if parenthood is mentioned in a letter, do not discuss it). Societies can help letter writers by providing evidencebased guidance (see, for example, Dutt et al., 2016, and references therein). There is a helpful online detector of gender bias at: https://www.tomforth.co.uk/genderbias/ (last access: 30 April 2020).

The chair of the selection committee could benefit from meeting with staff and becoming clear on the procedure and processes. In addition, it is helpful to learn how to manage a group discussion so that every member can speak and be heard.

\subsubsection{Maintain focus on the award's criteria}

One of the most important considerations for improving diversity and representation in honours and awards processes is to evaluate the award criteria. The committee should establish an evaluation rubric to ensure that all nomination packages are evaluated fairly. An evaluation rubric should clearly outline a system for ranking or categorizing nomination packets. For example, each criterion could be ranked using a point system, or specified criteria could be categorized based on a pass/fail system. "Excellence" is a hazy concept and what exactly is meant by this should be agreed upon by all members before evaluation begins.
The evaluation rubric should be decided upon by the entire committee before any application review begins, with ample time for committee members to ask clarifying questions or to make any changes to a previously used rubric. Confirm that the award criteria listed on the nomination call align with the award criteria identified on the rubric. For example, if a committee is evaluating a teaching award and a committee member wishes to discuss teaching pre-college students, is that an explicitly stated criterion in the award announcement or does such teaching constitute "service"? Another best practice when using evaluation rubrics is to include representative examples for each of the criteria being evaluated. If the criteria are weighted, then that should also be transparent in the award announcement.

When there are a large number of nominees, "grading fatigue" can impact the decisions made during the evaluation process. There are several strategies that can be used to lessen the impact of fatigue. For example, you can reduce the number of applications that an individual member has to review by randomly assigning them in advance. To ensure thoroughness, make sure that one application is reviewed by a minimum of three committee members. This process helps support a fair first cut to reduce the pool and lighten the load of work on selection committee members. It is important that all committee members should agree on how this first round of cuts will happen before beginning.

Lastly, the evaluation rubric must be a living document. At the end of each selection cycle, the rubric, including metrics, representative examples, etc., should be reviewed by the selection committee. Questions to guide this wrap-up review and discussion may include:

- What worked well?

- What didn't work or was particularly challenging during the process?

- What could be further clarified or defined for future use?

- What will the process be to make changes as necessary (i.e. majority vote or full consensus)?

- How were criteria adhered to?

- How do we cope with straying from criteria in the future?

Another way to streamline selection adopted by one AGU Section, is to require letters of support only for "short list" nominees, after the committee has determined who are the top 5-10 nominees. Feedback is provided to unsuccessful nominators.

All criteria used in evaluation should be clear in the ad for the award. Criteria should evolve as we learn more about evaluative processes. AGU no longer has an entry on submission forms for numeric shortcuts such as the $h$-index because of the potential error and bias. A problematic metric used to 
evaluate awards for graduate students in the US is the Graduate Records Examinations (GRE) score. There are multiple levels of bias and barriers related to GRE scores, including socioeconomic status (i.e. access to tutors, study materials, or cost of taking the test), and test anxiety (i.e. stereotype threat) that can significantly impact a student's score.

\subsubsection{Ground rules for meeting(s)}

Additional training for the selection committee chair on how to facilitate productive meetings is another valuable tool. The first committee meeting should establish ground rules for discussions. As in all other workplace meetings, having an agreed upon set of ground rules for respectful conversations is a great first step. These ground rules can be developed by the committee in advance, or perhaps there is already a process outlined by the society that can be provided by the staff. Behavioural ground rules should be established (e.g., "We will not be discussing candidates' parenthood, our personal relationship with the nominator or support letter authors"). The chair should keep the discussion focused on the criteria and ensure every member has a chance to speak. All members of the selection committee should agree to treat one another with respect.

\subsection{Additional strategies to improve honours programs}

\subsubsection{Maintain demographic data}

An oversight committee should work with staff to stay on top of membership, nominee, and awardee data. Pertinent information should be communicated to selection, canvassing, and other concerned committees. Consistent data collection is needed to watch for trends that can identify areas for growth (correction?) in the honours process. For example, AGU has identified a need for more accurate data concerning its US members who identify with under-represented racial and ethnic groups as current demographic data are insufficient. There is also a growing community of LGBTQ+ within the AGU community who are working to uncover and celebrate a long invisible history of contributions from geoscientists who identified as LGBTQ+. We would also like to acknowledge that the majority of bias and underrepresentation work in STEM has focused on a push for gender parity. However, by assuming a binary gender paradigm, we have negatively biased against a population of the STEM workforce who may instead identify as transgender, genderfluid, agender, etc. Professional societies need to ensure that there is a safe, voluntary way to acknowledge these identities in these spaces.

\subsubsection{Hold nominators and nominees accountable for good behaviour}

The scientific community has long considered ethical behaviour to be a primary qualification of practicing science.
Yet for hundreds of years, this definition of ethical behaviour has only addressed specific aspects of our work, such as data collection and handling, publication and authorship roles, and communicating our work with the local communities that we work with. We have spent decades ignoring the fact that ethical scientists must also treat humans in an ethical way. In 2017, AGU developed a new Ethics Policy that specifically included behaviours of bullying, harassment and discrimination as forms of scientific misconduct, on a par with data falsification and plagiarism (McPhaden et al., 2017). This was a big first step forward towards creating a diverse and inclusive AGU membership. Since the announcement of this new ethics policy, more professional societies in the geosciences are following AGU's lead to develop more comprehensive codes of conduct (Schneider et al., 2018).

Not only does this code of ethics address these behaviours, it has consequences for violators. The process of providing an award for AGU also includes nominators and nominees reading and agreeing to AGU's Ethics Policy. Any violation of this policy must be revealed to the AGU Ethics office. Such a revelation does not preclude a nominee from receiving an award but may generate a deeper investigation to ensure that awardees exemplify the principles stated in the Ethics Code. In addition, selection committee members must abide by the Conflict of Interest code, and recuse themselves from deliberation of nomination packets of friends, relatives, and other close personal connections (https://ethicsandequitycenter.org/, last access: 30 April 2020).

\subsubsection{Streamlining the nomination process}

Could the whole process be made simpler? What are the minimum number of documents, the minimum amount of information, that is necessary to fairly and fully evaluate a nominee? The Hydrology Section of AGU has a two-step process for evaluation. Supporting letters are not required until the second step, which follows an initial evaluation of nominations. This simplifies the process for nominators, who can use the selection committee's feedback to improve the primary nomination.

Technology can be a valid tool to assist in streamlining nomination processes. Has the professional society examined the process for nomination to see if technology or other changes could make the process more efficient? If so, how would committee members receive training on how to use it? This is an especially important consideration because committee members and chairs should rotate off after serving a defined term. Gathering feedback at the end of each process from committee members on what worked and what did not work can help professional societies better prepare for the next nomination cycle or to make changes as problems arise.

An additional component of streamlining the nomination process is providing feedback to the nominators each year. It is essential that nominators receive feedback on unsuccess- 
ful nominations. This is a mentoring process and over time should improve nomination packets. This includes gathering feedback from each committee member on the strengths and weaknesses of the nomination packet and formatting the feedback into a document that clearly outlines recommendations for future submissions. Depending on the number of nominations received for a particular award or honour, technology could be an important asset to assist with this task.

\subsubsection{Program review}

It is useful to review honours programs periodically, perhaps with a separate review committee that is provided with awards data from the preceding five to ten years. Questions to consider during a review include:

- Are there sufficient nominations?

- Does the gender and other pertinent demographic data of the awardees favourably compare to the society's membership or to the section?

- Is it time to sunset an award because of lack of nominations or greater relevance of a different disciplinary area?

- What is the process for sunsetting an award?

- Are the names of the awards (1) relevant to early career scientists and (2) representative and inclusive of the organization's membership?

- Does the award uphold the overall values of the organization?

\section{A path towards fair representation}

Honours and Awards Programs remain vital to advancing science, education, and outreach by highlighting the achievements and value of these endeavours to the broader community (e.g., Stewart and Valian, 2018). The challenge of ensuring that awardees reflect a diverse pool of scientists both in professional societies and worldwide can be mitigated by closely examining key decision points in the process. Professional societies should be taking deliberate steps to (1) inform and engage members of the awards they offer, (2) provide a transparent view of how the nomination process works, and (3) ensure adequate training and support for selection committees to be able to make fair decisions. Individuals who serve on these committees or who do the work to compile nomination packets should also ensure that they do the work to be trained on best practices. If a professional society doesn't offer it, ask why. As members, we should be encouraging our professional societies to collaborate with other societies that are establishing best practices. Finally, societies that are establishing these best practices need to disseminate this information out to the scientific community (and beyond!).
Data availability. We use AGU-supplied data on their membership demographics and Honors demographics, accessible here: https: //www.agu.org/-/media/Files/AGU_Membership_Demographics_ 2018.pdf, https://www.agu.org/-/media/Files/Learn-About-AGU/ 2014-2019-Honors-Program-Diversity-Report.pdf Both documents are accessed from this page: https://www.agu.org/ learn-about-agu/about-agu/diversity-and-inclusion (AGU, 2020).

Author contributions. All authors contributed to ideas, text, and figure.

Competing interests. The authors declare that they have no conflict of interest.

Disclaimer. The views or opinions expressed herein are those of the authors and do not necessarily reflect the views of the National Oceanic and Atmospheric Administration or the US Department of Commerce.

Special issue statement. This article is part of the special issue "Diversity and equality in the geosciences (EGU2019 EOS6.1 \& US4, AGU2018 ED41B, JpGU2019 U-02)". It is a result of the AGU Fall Meeting 2018, Washington, United States, 10-14 December 2018.

Acknowledgements. We wish to thank the many people with whom we have worked and discussed the ideas presented here, particularly AGU Honours staff, Leah Bland, Antonio Covington, Chelsea Fuller, Artesha Moore and not least, Rob Rader. We have cumulatively served on AGU Honours and Recognition Committee for over fifteen years and greatly appreciate the service and input from our fellow committee members. We wish to thank Alberto Montanari and an anonymous reviewer for their helpful suggestions to improve the manuscript.

Review statement. This paper was edited by Claudia Jesus-Rydin and reviewed by Alberto Montanari and one anonymous referee.

\section{References}

AGU: Diversity, equity, and inclusion at AGU, available at: https://www.agu.org/learn-about-agu/about-agu/ diversity-and-inclusion, last access: 30 April 2020.

AWIS (Association for Women in Science): Avoiding implicit bias: Best practices for award selection committees, available at: https://awis.site-ym.com/page/Awards_Recognition (last access: 1 January 2020), 2011.

Ball, J.: A pressing need for gender balance in AGU Honors nominations, EOS T. Am. Geophys. Un., 95, 80, https://doi.org/10.1002/2014EO090005, 2014.

Ball, J., Davidson, E., Holloway, T., Holmes, M. A., McKenzie, J. A., Mukasa, S., Paredes, B., Pieters, C., Sivapalan, M., and 
Vrugt, J.: Improving your success in AGU honors, EOS T. Am. Geophys. Un., 96, https://doi.org/10.1029/2015EO026143, 2015.

Bertrand, M. and Mullainathan, S.: Are Emily and Greg more employable than Lakisha and Jamal? A field experiment on labor market discrimination, Am. Econ. Rev., 90, 991-1013, https://doi.org/10.1257/0002828042002561, 2004.

Boring, A., Ottoboni, K., and Stark, P. B.: Student evaluations of teaching (mostly) do not measure teaching effectiveness, Science Open Research, https://doi.org/10.14293/S21991006.1.SOR-EDU.AETBZC.v1, 2016.

Carnes, M., Geller, S., Fine, E., Sheridan, J., and Handelsman, J.: NIH Director's Pioneer Awards: Could the selection process be biased against women?, J. Womens Health, 14, 684-691, https://doi.org/10.1089/jwh.2005.14.684, 2005.

Débarre, F., Rode, N. O., and Ugelvig, L. V.: Gender equity at scientific events, Evolution Letters, 2, 148-158, https://doi.org/10.1002/evl3.49, 2018.

Dutt, K., Pfaff, D. L., Bernstein, A. F., Dillard, J. S., and Block, C. J.: Gender differences in recommendation letters for postdoctoral fellowships in geoscience, Nat. Geosci., 9, 805-808, https://doi.org/10.1038/ngeo2819, 2016.

Fine, R. and Paredes, R.: Aligning the Honors Program with AGU's Mission, EOS T. Am. Geophys. Un., 93, 329-329, https://doi.org/10.1029/2012EO340008, 2012.

Hanson, R. B., Wooden, P., and Lerback, J.: Age, gender, and international author networks in the Earth and Space Sciences: Implications for addressing implicit bias, Earth and Space Science Open Archive, https://doi.org/10.1002/essoar.10501091.1, online first, 2019.

Holmes, M. A., Asher, P., Farrington, J., Fine, R., Leinen, M. S., and LeBoy, P.: Does gender bias influence awards given by societies? EOS T. Am. Geophys. Un., 92, 421, https://doi.org/10.1029/2011EO470002, 2011.

Holmes, M. A., O'Connell, S., and Dutt, K. (Eds.): Women in the geosciences: practical, positive practices toward parity, John Wiley \& Sons, 2015.

James, A., Chisnall, R., and Plank, M. J.: Gender and societies: a grassroots approach to women in science, Roy. Soc. Open Sci., 6, 190633, https://doi.org/10.1098/rsos.190633, 2019.

Jaynes, A. N., MacDonald, E. A., and Keesee, A. M.: Equal representation in scientific honors starts with nominations, EOS T. Am. Geophys. Un., 100, https://doi.org/10.1029/2019EO117855, 2019.

Johnson, D. R.: Women of color in science, technology, engineering, and mathematics (STEM), New Directions for Institutional Research, 2011, 75-85, 2011.

Kahneman, D.: Thinking, fast and slow, Macmillan, New York, NY, USA, 499 pp., 2011.

King, M. M., Bergstrom, C. T., Correll, S. J., Jacquet, J., and West, J. D.: Men set their own cites high: Gender and self-citation across fields and over time, Socius, 3, 1-22, https://doi.org/10.1177/2378023117738903, 2017.

Lincoln, A. E., Pincus, S. H., and Leboy, P. S.: Scholars' awards go mainly to men, Nature, 469, 472-472, https://doi.org/10.1038/469472a, 2011.

Lincoln, A. E., Pincus, S., Koster, J. B., and Leboy, P. S.: The Matilda Effect in science: Awards and prizes in the US, 1990s and 2000s, Soc. Stud. Sci., 42, 307-320, https://doi.org/10.1177/0306312711435830, 2012.

Macnell, L., Driscoll, A., and Hunt, A. N.: What's in a name: Exposing gender bias in student ratings of teaching, Innovative Higher Education, 40, 291-303, https://doi.org/10.1007/s10755014-9313-4, 2015.

Madera, J. M., Hebl, M. R., and Martin, R. C.: Gender and letters of recommendation for academia: agentic and communal differences, J. Appl. Psychol., 94, 1591-1599, https://doi.org/10.1037/a0016539, 2009.

Madera, J. M., Hebl, M. R., Martin, R., and Valian, V.: Raising doubt in letters of recommendation for academia: gender differences and their impact, J. Bus. Psychol., 34, 287-303, https://doi.org/10.1007/s10869-018-9541-1, 2019.

Maliniak, D., Powers, R., and Walter, B. F.: The gender citation gap in international relations, Int. Organ., 67, 889-922, https://doi.org/10.1017/S0020818313000209, 2013.

Malcom, S. M., Hall, P. Q., and Brown, J. W.: The double bind: The price of being a minority woman in science, American Association for the Advancement of Science, Washington, DC, USA, available at: https://pdfs.semanticscholar.org/699a/ 3ce375c0eb4bc0ad8a6c9057a1477031f4a3.pdf (last access: 1 January 2020), 1975.

Malone, K. R. and Barabino, G.: Narrations of race in STEM research settings: Identity formation and its discontents, Sci. Educ., 93, 485-510, 2009.

Malouff, J. M. and Thorsteinsson, E. B.: Bias in grading: A metaanalysis of experimental research findings, Aust. J. Educ., 60, 245-256, https://doi.org/10.1177/0004944116664618, 2016.

Mason, S., Marchetti, C., Bailey, M., Baum, S., and Valentine, M.: Faculty awards at a large private institution: an indicator of evolving university values?" in: American Society for Engineering Education Annual Conference and Exposition Conference Proceedings, 15-18 June 2014, Indianapolis, IN, USA, 2014.

McPhaden, M. J., Gunderson, L., and Williams, B.: AGU revises its integrity and ethics policy, EOS T. Am. Geophys. Un., 98, https://doi.org/10.1029/2017EO082469, 2017.

Moss-Racusin, C. A., Dovidio, J. F., Brescoll, V. L., Graham, M. J., and Handelsman, J.: Science faculty's subtle gender biases favor male students, P. Natl. Acad. Sci. USA, 109, 16474-16479, https://doi.org/10.1073/pnas.1211286109, 2012.

Mukasa, S.: Underrepresentation of Women and Minority Awardees in Geoscience Societies, Element Magazine, 5, 77-78, http:// www.elementsmagazine.org/toc/toc_v5n2.pdf, 2009.

NSF (National Center for Science and Engineering Statistics, National Science Foundation): Doctorate Recipients from U.S. Universities: 2018, Special Report NSF 20-301, Alexandria, VA, available at: https://ncses.nsf.gov/pubs/nsf20301/ (last access: 30 April 2020), 2019.

O’Meara, K., Kuvaeva, A., and Nyunt, G.: Constrained choices: A view of campus service inequality from annual faculty reports, J. High. Educ., 88, 672-700, 2017.

Posselt, J. R., Chen, J., Dixon, P. G., Jackson, J. F. L., Kirsch, R., Nuñez, A.-M., and Teppen, B. J.: Advancing inclusion in the geosciences: An overview of the NSF-GOLD program, Journal of Geoscience Education, 67, 313-319, https://doi.org/10.1080/10899995.2019.1647007, 2019.

Quardokus Fisher, K., Kaufman, E., Calagna, O., Myles, L., Brinkworth, C., Simmons, D. R., and Dixon, P. G.: Devel- 
oping scientists as champions of diversity to transform the geosciences, Journal of Geoscience Education, 67, 459-471, https://doi.org/10.1080/10899995.2019.1618692, 2019.

Schmader, T., Whitehead, J., and Wysocki, V. H.: A linguistic comparison of letters of recommendation for male and female chemistry and biochemistry job applicants, Sex Roles, 57, 509-514, https://doi.org/10.1007/s11199-007-9291-4, 2007.

Schneider, B. B., Holmes, M. A., and Marin-Spiotta, E.: Sexual Harassment in the Sciences: Response by Professional Societies, American Geosciences Institute Geoscience Currents, 125, available at: https://www.americangeosciences.org/sites/default/ files/currents/Currents-125-SexualHarassment.pdf (last access: 30 April 2020), 2018.

Stewart, A. J. and Valian, V.: An inclusive academy: Achieving diversity and excellence, MIT Press, Cambridge, MA, USA, 373414, 2018
Trix, F. and Psenka, C.: Exploring the color of glass: Letters of recommendation for female and male medical faculty, Discourse Soc., 14, 191-220, 2003.

Valian, V.: Why so slow?: The advancement of women, MIT Press, Cambridge, MA, USA, 1999.

Van Miegroet, H.: Gender equity deserves the attention of our societies, Crops, Soils, Agronomy News, 61, 28-30, https://doi.org/10.2134/csa2016-61-7-10, 2016.

Williams, J. C.: Double jeopardy? An empirical study with implications for the debates over implicit bias and intersectionality, Harvard Journal of Law \& Gender, 37, 185, available at: https://harvardjlg.com/wp-content/uploads/sites/19/2012/01/ 2014.5.pdf (last access: 1 January 2020), 2014. 